KRONOS | AGOSTO 2021-ENERO 2022 | vol. $02 \mid$ n. ${ }^{\circ} 1$

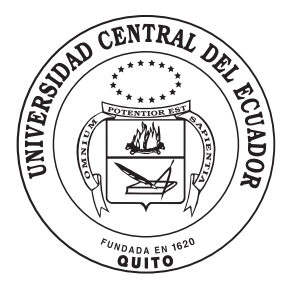

ISSN-I 2631-2840 | ISSN-E 2631-2859

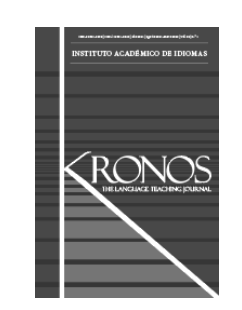

\title{
MAKING SENSE OF BAD ENGLISH
}

Peterson, Elizabeth. (2020), eBook, Oxford

Alexánder Padilla

Universidad Central del Ecuador (Ecuador)

https://orcid.org/0000-0001-5059-3199
Recibido: 30 de marzo 2021

Aprobado: 30 de abril 2021

DoI:10.29166/kronos.v2i1.2614
To recognize what is or what is not an appropriate use of English, language scientist have disposed the official term «Standard English». If so, what does this term really mean? and what were the conditions and bounds where this term was created? in consequence, who are the people that really speak in this strict way? This book discusses through an anthropological and linguistic way the term "good English». Thus, in general words the author discusses: How can somebody know whether his use of English is appropriated or not? What are the causes of such distinction (good/ bad) in real practices using this language? Moreover, the specific objective beyond the common negative answer about not standard English, this book offers an explanation from the social, cultural and historical facts about the meaning of being an English user in different parts of the world.

This book is divided in two parts, the first part contains 5 chapters which focus on the explanation of the relation between appropriated and bad English, and its persistence and reproduction in different settings. The second part is divided in 5 chapters, then they focus on the analysis of the linguistic manifestation of some cases of study, such as, the mother tongue or lingua franca through the roles of social, historical and geographical factors.

The first part explains the social construction of English regarding the people's believes about the acquisition of a new language or the natural way of speaking in native countries. Thus, this part explains that speaking English becomes natural in native countries. Standard English is a term which meaning is discussed throughout the book dismissing the idea of the universal truth. The author argues that Standard English (good English) is not recognized as a universal truth, but as a social construction which really depends of the social circumstances.

The important elements discussed are the preconceived notions which are called language ideologies.
Language ideologies are acquired implicitly in life in an unconscious way and they led to simplify the distinction of the features of the language. According to this distinction in the language, people are able to judge whether somebody speaks appropriated or not. Besides, it allows to recriminate and separate who speaks well and who doesn't. In fact, the book shows cases of linguistic research and surveys; they indicate that students from native countries, (Us students for example) are considered speakers with the perfect use of Standard English. However, us students consider themselves imperfect speakers due to the fact that exist an inferiority toward British pronunciation because their pronunciation is considered as that one that is truly correct.

Furthermore, the book offers the perspective of users of English in some places where English is not the mother tongue. In these kind of environments English users tend to speak English with a wide variety of styles around the world, adding a sort of mixture of local words and phrases. Again, not mother tongue English users are considered unappropriated users of this language, hence the distinction becomes the legitimation of a social hierarchy and control. Then, the author explains how the accent, dialects, etc. is an element of prestige or social class; showing the example of the results of a study of surveys applied in us and UK users. At the end of this part, the author points out the causes and the negative consequences of speaking differently, it means, out of the standard English, such as, the segregation, isolation, injustice and discrimination in social relations.

The second part of the book is made of linguistic manifestation of English presented in some cases of study such as: mother tongue acquisition of Standard English, African American English, Singlish, New Delhi English and English as a lingua franca. These cases of study constitute the attitudes developed from different 
users of English and their own point of view. Thus, in this part of the book the author explains several cases which are located in countries which mother tongue is English, however there are some differences among them. These differential facts are caused due to the roles of linguistic tendencies, social factors, and historical factors. For instance, one of the examples in the cases of study is the specific words, accents or phrases that distinguish and identify one group of people from other, due to the people circumstances or the distinction related to race or ethnicity.

The case of study about the use of English as a lingua franca in the book, presents people who already have the enough knowledge of English; however, English as a lingua franca is seen as the modification or adaptation system for their users that share features in the same group of speakers which is called similect. In spite of these kind of users who do not share a mother tongue, there is a tendency to focus on the practical message and transmit it to different backgrounds but without sounding as a native speaker. Then, the book contains an exhaustive analysis of the sound and pronunciation of vowels, consonants and accents according to the vernacular region of the user.

Making sense of Bad English is a book which offers a new perspective to the users of this language; further- more, it leads to know new perspectives according to the "good» use the language and it's benefits of an appropriate speaking as much as the different nuances of users around the world. The author approaches English as a sociolinguistic phenomenon and its implications in real life, according to the relationships among other users. Thus, the book reconstructs the general idea of «bad English» not like a negative condition. It rather offers some empirical descriptions which support the facts and history behind the linguistic difference, even in native English countries. The book also describes the actual situation of the new users of English, as much as their relation, adaptation, variation and changes carried out from their own users in order to obtain acknowledge.

This book is about a linguistic issue however the author expresses it in a simple and practical way in the framework and theoretical discussion. So, the author has focused her efforts in the content and the information of the uses of English instead of the form and the technical terms. For this reason, the book is easier to comprehend and accessible for a wider range of public, from English users, teachers to linguistics and sociologists. 